\title{
LA FUNCIÓN DE PROPOSICIÓN Y ADMISIÓN DE PRUEBA EN LA AUDIENCIA PREVIA
}

\author{
Xavier Abel Lluch \\ Director del Instituto de Probática y Derecho Probatorio \\ Facultad de Derecho - ESADE \\ Universidad Ramón Llull
}

\begin{abstract}
SuMARIo. 1. Introducción.-2. Apertura período probatorio. Impulso de oficio.-3. La proposición de los medios de prueba.-4. El juicio sobre la admisión de los medios de prueba. 4.1. El juicio de admisión y el incidente de ilicitud. 4.2. La admisión de los documentos y dictámenes iniciales. 4.3. La limitación del número de testigos.-5. La impugnación de la resolución sobre la admisión de las pruebas.-6. La facultad judicial de integración probatoria (art. 429.1, II y III LEC).-7. El señalamiento del juicio.-8. Conclusiones.
\end{abstract}

\section{INTRODUCCIÓN.}

El presente estudio tiene por objeto el estudio de la función probatoria en la audiencia previa. Como es sabido, el legislador ha concentrado en este trámite procesal una pluralidad de funciones -conciliadora, saneadora de defectos procesales, delimitadora de los términos del debate y probatoria-. Esta última función probatoria, y más concretamente de proposición y admisión de los medios de prueba, tiene por finalidad fundamental la preparación del juicio.

Se analizarán cada uno de los aspectos contenidos en la regulación de los artículos 429 y 430 LEC, desde la forma y modo de proponer los medios de pruebas, hasta los presupuestos y caracteres del juicio de admisión de los medios de prueba, pasando por la novedosa y controvertida facultad que permite al juez efectuar una indicación de insuficiente probatoria (art. 429.1, II y III LEC), para terminar con los aspectos relativos al señalamiento del juicio.

\section{APERTURA PERIODO PROBATORIO. IMPULSO DE OFICIO.}

$\mathrm{Ni}$ en la audiencia previa del juicio ordinario -ni en la vista del juicio verbal- se precisa solicitar el recibimiento del juicio a prueba, sino que el período probatorio se abrirá, sin necesidad de previa petición de parte, por impulso de oficio.

Bajo la vigencia de la LEC de 1881, y en un proceso civil inspirado por la escritura, el impulso de la actividad probatoria, en orden a la solicitud del recibimiento a prueba y la proposición de las pruebas, correspondía a las partes. En la comparecencia del menor cuantía, se preveía que «si interesa al derecho de las partes el recibimiento a prueba del pleito, habrán de solicitarlo en el acto de la comparecencia» (art. 692.4; 
II LEC 1881). E incluso para el juicio de mayor cuantía se preveía que el juez recibiera el juicio a prueba en el caso de que todos los litigantes lo hubieren solicitado y en caso de existir oposición de algún litigante, y previa audiencia a los mismos, el juez debía decidir lo que estimara procedente (art. 550 LEC 1881). En la práctica forense, lo más habitual era solicitar el recibimiento del juicio a prueba en un otrosí del escrito de demanda, para evitar que el olvido en un momento posterior privara a la parte de su derecho a la prueba.

La LEC, con la finalidad de evitar «tiempos muertos», opta por el impulso de oficio en el recibimiento del juicio a prueba y en la proposición de los medios de prueba. El art. 429.1 LEC dispone que, en defecto de acuerdo de las partes para finalizar el litigio o existiendo hechos controvertidos, "la audiencia proseguirá para la proposición y admisión de prueba. Y mutatis mutandi existe una previsión similar para el juicio verbal, puesto que el art. 443.4 LEC, sobre el desarrollo de la vista, dispone que «si no hubiera conformidad sobre ellos [los hechos relevantes que funden las pretensiones de las partes], se propondrán las pruebas,...».

Jurídicamente el impulso es la facultad (judicial) o carga (de la parte) de hacer progresar el proceso, de dar continuidad a las actuaciones procesales promoviendo los trámites procesales correspondientes. Una vez desaparecida la necesidad -en expresión de SERra Domínguez la «anomalía»- de la solicitud del recibimiento del juicio a prueba dependiente de la voluntad de las partes, el impulso de la actividad probatoria es de ofico en cuanto a la apertura del juicio a prueba ${ }^{1}$. Se producirá cuando no exista conformidad sobre los hechos controvertidos (arts. 429.1 y 443.4 LEC), aun sin mediar petición de las partes ${ }^{2}$.

\section{LA PROPOSICIÓN DE LOS MEDIOS DE PRUEBA.}

La proposición de los medios de prueba tiene lugar en la audiencia previa (en el juicio ordinario) o en la vista (en el juicio verbal) que son actos presididos por la oralidad. La proposición de los medios de prueba debe efectuarse oralmente y de la misma quedará constancia en el acta de grabación que se extienda al efecto (art. 147 LEC).

${ }^{1}$ Serra Domínguez, M., «Liberalización y socialización del proceso civil. Las facultades del Juez en la legislación y en la realidad procesales», Revista de Derecho Procesal Iberoamericana, 1972, p. 535, afirma que «estando la prueba dirigida toda ella a formar la convicción judicial, se comprende que es el Juez el principal interesado en la correcta formación de la prueba y, por tanto, quien debe apreciar libremente su procedencia o improcedencia y en su caso dirigir todo el periodo probatorio».

${ }^{2}$ EtXeberría Guridi, J. F., «Consideraciones acerca de la audiencia previa al juicio en la nueva LEC (y II)», Diario La Ley, núm. 5379, de 20 de septiembre de 2001, p. 7. 
Existe un usus fori-admitido por la doctrina ${ }^{3}$ y la jurisprudencia ${ }^{4}-$ en virtud del cual los letrados, una vez formulada oralmente la proposición de los medios de prueba de que intenten valerse, acompañan una minuta de proposición de prueba que entregan al Juez o Secretario, en la que se contiene una enumeración separada de los medios de prueba, con identificación de cada uno de los propuestos, y de los nombres y direcciones de testigos y peritos.

Dicha minuta ofrece ventajas tanto para los letrados, cuanto para el propio juez. A los letrados les permite formular oralmente $-\mathrm{y}$ sin olvido- todos los medios de prueba o, en su caso, modular su propuesta a la vista de la proposición de medios efectuada de adverso o de la fijación de los hechos controvertidos. Al juez le facilita el juicio de admisión de los medios de prueba, porque puede tener a la vista «el listado» de los propuestos y también el libramiento de oficios para citación de testigos y peritos y de despachos para la obtención de los documentos.

No existe previsión legal del traslado de la minuta de proposición de los medios de prueba y es muy dudoso que tenga encaje en la previsión que obliga a dar copia de escritos y documentos a las demás partes (art. 273 LEC), en cuanto no es un «escrito» del proceso ni está previsto en trámite legal alguno, aun cuando puede resultar una cortesía procesal fundada en normas de deontología profesional o en observancia de la buena fe procesal (art. 247 LEC).

En caso de disconformidad entre la minuta de proposición de los medios de prueba y los propuestos oralmente, prevalecen éstos últimos por ser la audiencia previa -y también la vista del juicio verbal- un acto oral y no existir exigencia legal de aportar por escrito los medios propuestos.

Se ha planteado si cabe la renuncia a un medio de prueba (ej. interrogatorio de las partes o testigos) una vez admitido y con anterioridad a su práctica. A favor de la renunciabilidad se ha argumentado la vigencia del principio

${ }^{3}$ Ortells Ramos, M., Derecho Procesal Civil, 10ª ed., Thomson, Cizur Menor, 2010, p. 316, apunta «la forma del acto de proposición debe ser oral, pero no veo obstáculo a que, junto con la exposición oral de la prueba propuesta se acompañe y presente relación escrita con los datos precisos para preparar la práctica, en su caso, de cada medio propuesto (relaciones de nombres de testigos, datos de direcciones, etc.)».

${ }^{4}$ La Sentencia de la Audiencia Provincial de Asturias, secc. $1^{\text {a }}$, de 1 de febrero de 2011, FJ $2^{\circ}$ (La Ley 30748/2011) razona: «Es cierto que solo se presenta una factura de fecha 24 de septiembre de 1999, de material de obra y sin nombre del destinatario, sin embargo hay que considerar suficientemente probadas las obras cuyo importe se recoge en el informe pericial, tanto por dicho dictamen en el que se acompañan fotografías de las mismas, como por el reconocimiento de $\mathrm{D}^{\mathrm{a}}$ Julia, al que se ha hecho mención y por la prueba testifical, teniendo en cuenta que la parte interesó una prueba más amplia pero la Juez inadmitió las declaraciones de otros testigos cuyo llamamiento al pleito era precisamente para acreditar la realización de las distintas obras, como se explica en la minuta de prueba (folio 190) [...]» (La cursiva es mía). 
de aportación de parte en el proceso civil. En virtud de dicho principio a las partes corresponde la carga de la alegación y prueba de los hechos afirmados en su escrito de alegaciones. Así se recoge en el artículo 216 LEC -erróneamente rubricado principio de justicia rogada-al disponer que «los tribunales decidirán los asuntos en virtud de las aportaciones de hechos, pruebas y pretensiones de las partes, excepto cuando la ley disponga otra cosa». Si la parte tiene la facultad y la carga de proponer los medios de prueba de que intenta valerse, también debe tener la facultad de renunciar a los mismos, siempre que la renuncia se produzca con anterioridad a la práctica $\mathrm{y}$, por ende, desconociéndose el resultado que va arrojar su práctica ${ }^{5}$. Se añade, además, que el art. 288 LEC, rubricado sanciones por la no ejecución de la prueba en el tiempo propuesto, dispensa de la imposición de la sanción en el supuesto que el litigante desistiere de practicar una prueba si él la hubiese propuesto, admitiéndose normativamente el desistimiento con respecto a los medios de prueba propuestos.

En contra de la renunciabilidad se invoca el principio de adquisición procesal, que en la formulación de CHIOvENDA, significa que el resultado de las pruebas pertenece al proceso, con independencia de la parte que la haya propuesto $^{6}$ o en palabras de la STS de 9 de mayo de 2011 «el tribunal puede tomar en consideración, sin incurrir en vicio de incongruencia, las pruebas aportadas válidamente al proceso, cualquiera que sea la parte que las haya incorporado, en virtud el principio de adquisición procesal $»^{7}$. Se añade también que el hecho que una prueba se haya admitido, genera una expectativa sobre su práctica que puede verse frustrada de admitirse el desistimiento. Y también se alega que una vez admitido un medio de prueba (ej. interrogato-

5 En este sentido Montero Aroca, J., La prueba en el proceso civil, $7^{\mathrm{a}}$ ed., Civitas, Madrid, 2012, p. 114, para quien «la proposición de un medio de prueba por una parte, e incluso su admisión por el juez, no obliga a la parte a practicar ese medio, siendo indudable que la parte puede renunciar al mismo antes que se practique (Sentencia del Tribunal Supremo de 24 de julio de 1992)».

${ }^{6}$ Fue formulado por vez primera por Chiovenda, quien en sus Principios de Derecho Procesal afirma: «Del hecho de que las actividades procesales pertenecen a una relación única, derívase también otro principio importante, y es que los resultados de las actividades procesales son comunes entre las partes (adquisición procesal). En otras palabras, cuando la actividad de una parte es perfecta y completa para producir sus efectos jurídicos éstos pueden ser utilizados por la otra parte» (Principios de Derecho Procesal Civil, t.II, traducc. De J. Casáis y Santaló, Reus, Madrid, 1925, p. 205).

7 Sentencia del Tribunal Supremo, Sala $1^{\text {a }}$, de 9 de mayo de 2011, FJ $6^{\circ}$ (La Ley $62802 / 2011)$. Puede verse también sobre el principio de adquisición procesal el trabajo de Picó i Junoy, J., «El principio de adquisición en materia probatoria», La Ley, 2006, t.1, p. 1309 y ss, con abundante cita de jurisprudencia, y el de Corbal FernÁndez, J., «La adquisición procesal y la carga de la prueba», en La prueba en el proceso civil, Cuadernos de Derecho Judicial, núm. XXXIV/1993, CGPJ, 1993, particularmente pp. 150-173. 
rio de las partes o de testigos) las demás partes no proponentes de ese medio de prueba tienen derecho a participar en el interrogatorio.

Resultan más convincentes los argumentos contrarios a la renunciabilidad, y básicamente el principio de adquisición procesal, que a nuestro entender opera una vez recaído el juicio de admisión de los medios de prueba -sin necesidad de esperar a la práctica de la prueba-, y en virtud del cual se genera el derecho y la expectativa a su práctica. A efectos prácticos, una solución puede ser que habiéndose planteado por una parte la renuncia a un medio admitido el juez de traslado de dicha petición a la parte adversa, y si la misma se conforma, no haya ningún obstáculo en admitir la renuncia y si la parte adversa no se conforma, el juez resuelva lo procedente.

\section{EL JUICIO SOBRE LA ADMISIÓN DE LOS MEDIOS DE PRUEBA}

Entre la proposición y la práctica de la prueba media el juicio sobre la admisión o inadmisión de los medios de prueba. Con razón afirma MuÑoz SABATÉ que falta una reflexión sobre el juicio de admisión de los medios de prueba. Basta pensar, por un momento, la asimetría entre la posición del letrado -que tarda mucho tiempo en averiguar y proponer sus medios de prueba- y del juez -que emite su juicio de admisión o inadmisión- en una resolución oral e instantánea.

Un análisis del juicio sobre la admisión de los medios de prueba exige referirse a su naturaleza jurídica -la de un deber judicial-, los presupuestos de su ejercicio - la fijación de los hechos controvertidos y la proposición de prueba-, los parámetros legales de admisión -pertinencia, utilidad y licitudlos caracteres de la resolución judicial -oral, individualizada, motivada, expresa y recurrible-, el alcance de la máxime pro probatione y, finalmente, el juicio sobre la ilicitud de la prueba.

La proposición de los medios de prueba es una facultad y una carga de las partes, mientras el juicio sobre la admisión constituye un deber del juez, en el sentido que éste inexcusablemente debe pronunciarse sobre cada uno de

${ }^{8}$ Muñoz Sabaté, L., Fundamentos de prueba judicial civil L.E.C. 1/2000, Bosch, Barcelona, 2001, p. 239, señala el contraste entre «la cantidad y la calidad del trabajo que sule emplear un abogado en diseñar lo que yo llamo su fórmula probática necesariamente supera a la del juez al dictar su proveído de admisión».

${ }^{9}$ La tensión entre la carga de las partes y el deber del juez se recoge en la Sentencia del Tribunal Constitucional de 23 de junio de 1997, FJ $3^{\circ}$ (EDJ 1997/4019) en los términos literales siguientes: «Desde una perspectiva formal, el litigante tiene la carga, en su acepción procesal, de explicar razonadamente no sólo la conexión de cada prueba con el objeto procesal sino su importancia para la decisión del pleito, en cuyo doble aspecto reside la pertinencia, por venir a propósito y concernir a lo que está en tela de juicio. Una exigencia simétrica impone al juzgador la obligación de razonar también, en su caso, la inadmisión o impertinencia [...]. Aquí se plantea una vez más la tensión dialéctica entre la independencia del Poder Judicial, titular de la función jurisdiccional y la salvaguarda de las garantías constitucionales que nos corresponde, como se diseña en el art. $123 \mathrm{CE}$ ». 
los medios de prueba propuestos (art. 285.1 LEC), para admitirlos o denegarlos, sin que pueda omitir su resolución o diferirla a un momento posterior.

La admisión de los medios de prueba requiere la previa posición de los medios de prueba y la fijación de los hechos controvertidos. Sin la previa proposición de los medios de prueba, y a salvo de los supuestos de prueba de oficio, el juez no puede emitir su juicio de admisión o inadmisión de prueba. La fijación de los hechos se traduce en la dispensa de prueba de los hechos «sobre los que exista conformidad de las partes» (art. 281.3 LEC) y en la fijación de los controvertidos como una función específica-llamada por Alonso-Cuevillas «función sub-concretora» ${ }^{10}$ - de la audiencia previa y como precedente inmediato y necesario de la proposición de los medios de prueba.

Los parámetros o criterios legales de admisión de prueba se traducen en la pertinencia, utilidad y legalidad. Pertinencia, referida a la relación entre los medios de prueba propuestos y el objeto de la prueba. Utilidad, referida a la idoneidad del medio propuesto para acreditar el hecho discutido. Y legalidad, en cuanto observancia de las normas procesales -básicamente de forma y plazo- de proposición de prueba.

La decisión judicial admitiendo o denegando los medios de prueba propuestos se expresa mediante una resolución oral, individualizada, motivada, expresa y recurrible, debiéndose analizar cada uno de estos caracteres.

a) Oral. La oralidad, permite la resolución instantánea en la misma audiencia previa, sin posibilidad de diferirla en el tiempo ${ }^{11}$ e inaudita parte (sin necesidad de audiencia a la contraparte) $)^{12}$, y facilita el juicio sobre la admisión, permitiendo, a modo de ejemplo, que el juez indague sobre una prueba cuya admisión puede prima facie resultar dudosa o por la relación del testigo propuesto con los hechos controvertidos.

b) Individualizada. La resolución de admisión o inadmisión se extiende a todos y cada uno de los medios propuestos, por imperativo del art. 285.1 LEC, se hayan formulado en la proposición inicial o a raíz de la facultad de completar o modificar los medios de prueba cuando el juez hace uso de la normativa del art. 429.1, II y III LEC. Lo cual no impide, obviamente, que una vez admitido un medio de prueba (ej. interrogatorio de las partes o de

${ }^{10}$ Alonso-Cuevillas Sayrol, J., «La audiencia previa», en Instituciones del Nuevo Proceso Civil. Comentarios sistemáticos a la Ley 1/2000, vol. II, Dijusa, Barcelona, 2000, p. 166.

${ }^{11}$ Asencio Mellado, J. M., «El proceso civil práctico», t. IV, La Ley, 4ª ed., Madrid, 2010, p. 77; Velázquez Vioque, D., «El juicio sobre la admisión o inadmisión de los medios de prueba», Aspectos prácticos de la prueba civil, Bosch, Barcelona, 2005, pp. 110 y 120 .

12 Fernández Urzainqui, F. J., "Comentario al art. 285 LEC», en Comentarios a la nueva Ley de Enjuiciamiento Civil, t. II, Atelier, Barcelona, 2000, p. 1324. 
testigos), determinadas preguntas sean pertinentes y otras no, con lo cual la denegación del medio de prueba es parcial ${ }^{13}$.

c) Motivada. Es necesario razonar tanto la admisión cuanto la inadmisión de los medios de prueba, y particularmente su denegación, pues puede producir indefensión, susceptible de tutela a través del recurso de amparo ante el Tribunal Constitucional por violación del derecho a la utilización de los medios de prueba pertinentes para la defensa (art. 24.2 CE). La motivación de la inadmisión, sin llegar a ser exhaustiva, debe ser suficiente y comprensiva del razonamiento denegatorio, siendo deseable no abusar de fórmulas estereotipadas tales como «impertinente»o «inútil», sin una concreta referencia a las circunstancias del caso.

d) Expresa. La resolución judicial debe ser de admisión o inadmisión, y no sujeta a condición alguna ${ }^{14}$, de manera que la parte perjudicada por la admisión o inadmisión, en uso de su derecho a la tutela judicial efectiva, pueda impugnarla a través de los recursos oportunos.

e) Recurrible. La resolución sobre la admisión o inadmisión de los medios de prueba en la audiencia previa es recurrible a través de un recurso de interposición, substanciación y resolución oral (art. 285.2 LEC) $)^{15}$.

Resulta conveniente atender a la máxima pro probatione e incurrir en un posible exceso en la admisión de prueba que en su denegación ${ }^{16}$. Ahora bien, el recurso a la máxima pro probatione no es automático, sino que exigirá la previa fijación de los hechos controvertidos -pues sobre los hechos admitidos hay dispensa prueba (art. 281.3 LEC)-, la inexistencia de dudas sobre la admisión o inadmisión - pues existen supuestos que ofrecen pocas dudas- $\mathrm{y}$

13 Garcimartín Montero, R., «Comentario al art. 285 LEC», en Comentarios a la Ley de Enjuiciamiento Civil, vol.1, Aranzadi, Cizur Menor, 2001, p. 1016; Rodriguez TIRAdo, A. M., «El interrogatorio de testigos», en Instituciones del nuevo Proceso Civil, vol. II, Dijusa, Barcelona, 2000, p. 394.

${ }^{14}$ Asencio Mellado, J. M., en «El proceso civil práctico», ob. cit., p. 75, apostilla que «ni siquiera cabe una admisión ad cautelam para su práctica en un momento posterior a la ejecución».

15 Velázquez Vioque, D., «El juicio sobre la admisión de los medios de prueba», ob. cit., p.113 apunta como ventajas de la posibilidad de recurrir la admisión de las pruebas: 1) evitar dilaciones indebidas, zanjando la práctica de admitir incondicionalmente todas las pruebas; 2) clarificar el objeto del proceso; 3 ) razones de orden económico, en cuanto que la parte afectada por la admisión de pruebas superfluas, si posteriormente es condenada, habrá de soportar el pago de dichas pruebas.

${ }^{16}$ La jurisprudencia constitucional recuerda que la constitucionalización del derecho a la prueba implica «una nueva perspectiva y una sensibilidad mayor en relación con las normas procesales atinentes a ello, de suerte que deben los tribunales proveer a su satisfacción, sin desconocerlo no obstaculizarlo [el derecho a la prueba], siendo preferible en tal materia incurrir en un posible exceso en la admisión de pruebas que en su denegación» (Sentencia del Tribunal Constitucional, de 20 de febrero de 1986, FJ 8º, EDJ 1998/30). 
la concurrencia de un dubio, entendido como la concurrencia de una duda razonable sobre los criterios de pertinencia, utilidad o legalidad.

Se ha planteado si cada parte puede pronunciarse sobre la prueba propuesta de adverso con anterioridad al juicio de admisión (o inadmisión) del juez. En orden a la proposición de los medios de prueba se prevé que «la proposición de los distintos medios de prueba se hará expresándolos con separación» (art. 284 LEC) y que «el tribunal resolverá sobre la admisión de cada una de las pruebas que hayan sido propuestas» (art. 285.1 LEC), sin mayores concreciones procedimentales.

La parte actora formulará oralmente los medios de prueba de que intente valerse, acto seguido efectuará lo mismo la parte demandada, y a continuación debe recaer el juicio de admisión del juez, sin que exista una previsión legal en virtud de la cual cada parte pueda pronunciarse -y, en su caso, impugnar- los medios propuestos de adverso con anterioridad al juicio de admisión. Cuestión distinta es la existencia de una práctica forense, carente de sustrato normativo, en virtud de la cual el juez concede un turno de palabra a las partes con anterioridad a pronunciarse sobre la admisión de los medios de prueba, y que probablemente obedezca más a una comodidad judicial que a la observancia de un precepto legal.

El derecho a la contradicción y, más genéricamente, el derecho a la tutela judicial efectiva en su vertiente del derecho a los recursos, se salva mediante la previsión, con respecto al juicio ordinario, de un recurso de reposición oral contra la admisión o inadmisión de cualesquiera medios de prueba (art. 285.2 LEC). Se trata de un recurso de reposición de interposición, substanciación y resolución oral, todo ello en el mismo acto de la audiencia previa.

También se ha planteado si debe recaer una resolución sobre admisión o inadmisión de todos los medios de prueba en la audiencia previa o puede el juez diferir la admisión de algún medio de prueba a un momento posterior. La proposición de los medios de prueba es oral y concentrada en la audiencia previa -salvo, por supuesto, los supuestos de prueba anticipada (art. 293 LEC) o de diligencias finales (art. 435.1 LEC)-. Y el juicio sobre la admisión - $\mathrm{o}$, en su caso, inadmisión- de los medios propuestos debe contenerse en una única resolución emitida en la audiencia previa, sin posibilidad de diferir su pronunciamiento a un momento posterior o de condicionar su admisión. Todo ello a salvo de los supuestos de proposición subsidiaria (ej. pericial subsidiaria para el supuesto de no reconocimiento tras el interrogatorio de partes o de testigos de una determinada firma).

La exigencia de una resolución oral y expresa integra el derecho a la utilización de los medios de prueba pertinentes, elevado a rango constitucional (art. 24.2 CE), una de cuyas exigencias es el deber judicial de pronunciarse expresamente sobre la admisión o inadmisión de las pruebas propuestas, lo que permite al litigante reaccionar en forma contra el rechazo de una prueba, por lo que deben proscribirse las denegaciones condicionales de la prueba. 
En la práctica forense, el juicio sobre la admisión se exterioriza mediante la expresión «se admite o se inadmite», o también la expresión específica «pertinente o impertinente» en relación con cada uno de los medios de prueba propuestos. De ahí que el uso de la fórmula o cláusula de estilo «no ha lugar por ahora sin perjuicio de lo que en su día pueda acordarse para mejor proveer» ${ }^{17}$, u otras de análoga significación -tales como «sin perjuicio de acordarla para mejor proveer» ${ }^{18}-$, a menudo empleada para pronunciarse sobre la admisión del reconocimiento judicial, deba considerarse técnicamente incorrecta y jurídicamente inaceptable, en la medida que ni admiten ni rechazan la prueba. Y eventualmente pueden generar perplejidad, cuando no indefensión, a la parte proponente, la cual ignora la conducta procesal a seguir.

\subsection{El juicio de admisión y el incidente de ilicitud.}

Los criterios para la admisión de los medios de prueba son los de pertinencia -relación entre la prueba propuesta y el thema probandi-, la utilidad -idoneidad del medio de prueba propuesto para acreditar el hecho controvertido- y legalidad -observancia de las normas de forma y tiempo en la proposición de los medios de prueba- $\mathrm{y}$ todos ellos aparecen recogidos en el art. 283 LEC, bajo la rúbrica de «impertinencia o inutilidad de la actividad probatoria».

El incidente de ilicitud, carente de precedentes en la LEC de 1881, es el procedimiento adecuado para evitar la práctica de una prueba admitida y que pudiera resultar ilícita, en referencia a las pruebas ya admitidas (art. 287 LEC). No es posible que el tribunal pueda soslayar el incidente de ilicitud e inadmitir de oficio y ab limine una prueba por ilícita, como hace al inadmitir una prueba por impertinente, inútil o ilegal (art. 283 LEC) ${ }^{19}$. Tal actuación

${ }_{17}$ Sentencia del Tribunal Supremo, Sala $1^{\text {a }}$, de 18 de mayo de 1993, FJ $5^{\circ}$ (EDJ 1993/4677).

${ }_{18}$ Sentencia del Tribunal Supremo, Sala $1^{\text {a }}$, de 8 de febrero de 2000, FJ $4^{\circ}$ (EDJ 2000/516).

19 En el mismo sentido Asencio Mellado, J. M., «El proceso civil práctico», ob. cit., pp. 124-125; PICó i JunOY, J., «La prueba ilícita y su control judicial en el proceso civil», en Aspectos prácticos de la prueba civil, Bosch, Barcelona, 2005, pp. 39-40; FERNÁNDEZ URZAINQUi, F. J., «Comentario al art. 287 LEC», en Comentarios a la nueva Ley de Enjuiciamiento Civil, t. II, Atelier, Barcelona, 2000, p. 1341. En sentido distinto, De LA Oliva SAntos, A., «Comentario al art. 287», en Comentarios a la Ley de Enjuiciamiento Civil, Civitas, Madrid, 2001, p. 524; Garcimartín Montero, R., «Comentario al art. 287 LEC», en Comentarios a la Ley de Enjuiciamiento Civil, vol. I, Aranzadi, Cizur Menor, 2001, p. 1026, para quien «la previsión del art. 287 LEC es absurda, pues lo más deseable -ante una norma que vulnera derechos fundamentales- es que ni siquiera llegue a formar parte del proceso»; Seone Spielbergerg, J. L., La prueba en la Ley de Enjuiciamiento 1/2000. Disposiciones Generales y Presunciones, 2a ed., Aranzadi, Cizur Menor, 2007, p. 300. 
de oficio debería estar expresamente prevista en la Ley, y no existe en tal sentido previsión normativa.

Por el contrario, el legislador ha optado por un incidente particular de ilicitud, en el que salvando la contradicción, de singular trascendencia para la parte proponente de la prueba supuestamente ilícita, recaiga una resolución ad hoc, con anterioridad a la práctica de la prueba, y susceptible de un recurso de reposición, de interposición, substanciación y resolución en el mismo acto del juicio o de la vista (art. 287.2 LEC).

Cuestión distinta, y no prevista por la LEC, es si el juez puede de oficio cuestionar la licitud de una fuente de prueba en el momento de dictar sentencia ${ }^{20}$. No obstante el legislador haya establecido como momento preclusivo para la denuncia de la ilicitud el inicio de la práctica de la prueba (arts. 287,1, II y 433.1 LEC), con la finalidad fundamental de evitar la «contaminación» del juzgador, si en el momento de dictar sentencia el juez advierte la ilicitud de la prueba practicada entiendo posible que pueda suscitar de oficio, e incluso a instancia de parte, un incidente de nulidad de actuaciones. Y salvando nuevamente la contradicción sobre «el concreto extremo de la referida ilicitud», declarar la ilicitud de la prueba, todo ello con fundamento en los arts. 225.5 y 227.2 LEC y 11 LOPJ y la doctrina constitucional que sanciona con nulidad la prueba obtenida con vulneración de los derechos fundamentales ${ }^{21}$.

\subsection{La admisión de los documentos y los dictámenes en los escritos ini- ciales.}

La admisión de los documentos, dictámenes o instrumentos -al igual que los restantes medios de prueba- solo puede tener lugar en el momento de admisión de los medios de prueba, que es la audiencia previa en el juicio ordinario (art. 429.2 LEC), aun cuando por exigencias del principio de igualdad o buena fe procesal tales documentos, dictámenes o instrumentos se hayan aportado con los escritos iniciales de alegaciones.

La aportación prueba documental, al igual que los dictámenes de periciales y los instrumentos, está sometida a estrictas reglas de preclusividad. La regla general es que los documentos fundamentales y los dictámenes a instancia de parte se han de aportar junto con el escrito de demanda y de contestación a la demanda (art. 265.1 LEC) ${ }^{22}$, sin perjuicio de acudir al sistema

${ }^{20}$ Ortells Ramos, M. y otros, Derecho Procesal Civil, $12^{\mathrm{a}}$ ed., Aranzadi, Cizur Menor, 2010 , p. 366, censura que no se haya previsto el efecto de inadmisión de la prueba ilícita, y afirma que «el tribunal tiene potestad de oficio para apreciarla».

${ }^{21}$ Asencio Mellado, J. M., en «El proceso civil práctico», ob. cit., p. 125; FernándeZ URZAINQUi, F. J., «Comentario al art. 287 LEC», ob. cit., p. 1340.

22 Montero Aroca, J., La prueba en el proceso civil, ob. cit., pp. 297-298, razona que el deber de aportación inicial de los documentos fundamentales radica en el principio de igualdad de las partes, así como en las especiales circunstancias que concurren en los 
de designación (art. 265.2 LEC) o que el actor pueda aportar en la audiencia previa los documentos, medios, instrumentos, dictámenes o informes relativos al fondo del asunto, cuyo interés o relevancia sólo se ponga de manifiesto a consecuencia de las manifestaciones efectuadas por el demandado (art. 265.3 LEC). La inobservancia de la carga de la aportación inicial de los documentos o de los dictámenes a instancia de parte se traduce en la preclusión de su aportación en un momento posterior (art. 269 LEC), salvo en los supuestos legales en que se permite una excepcional y tasada aportación posterior (arts. 270 y 272 LEC) 2 $^{23}$.

Dos argumentos adicionales confirman nuestra posición. Por una parte, en el auto de admisión de la demanda, y en el que se acuerda dar traslado al demandado para que conteste a la demanda, no existe ninguna previsión que el tribunal tenga que pronunciarse sobre los documentos aportados con la demanda (art. 404 LEC). Y, por otra parte, la «impugnación» de los documentos y de los dictámenes tiene lugar en la audiencia previa (art. 427.1 y 2 LEC), previsión carente de significado si los documentos ya estuvieren admitidos con los escritos de alegaciones.

No existe un trámite anterior a la admisión de las pruebas que el de la audiencia previa, una vez fijados los hechos controvertidos, y no debe confundirse la existencia de una carga procesal -aportación de documentos y dictámenes con los escritos de alegaciones- cuya inobservancia determina la preclusión, con el juicio de admisión de los medios de prueba, que exigirá siempre la existencia de hechos controvertidos y se pospone para la fase de la audiencia previa ${ }^{24}$. Por imperativo legal, la admisión de documentos y dictámenes a instancia de parte se producen al final de la audiencia previa, una vez propuestos todos los medios de prueba ${ }^{25}$. Ello resulta compatible con la existencia de una carga de aportación inicial de documentos y dictámenes, cuya finalidad es evitar la vulneración del derecho de defensa y contradicción que se produciría si una de las partes no pudiera contrastar los documentos y dictámenes en un momento procesal para ello en la fase de alegaciones.

documentos (no precisan práctica posterior, tiene especial valor probatorio respecto las demás pruebas y suelen recoger los hechos que identifican la pretensión).

${ }^{23}$ Más ampliamente en nuestro trabajo, La prueba documental, Bosch, Barcelona, 2010, pp. 90-99.

${ }^{24}$ En este sentido, LóPEz Simó, F., Disposiciones generales sobre la prueba, La Ley, Madrid, 2001, pp. 79-80; Banacloche PalaO, J. y otros, El tratamiento de las cuestiones procesales y la audiencia previa al juicio ordinario en la Ley de Enjuiciamiento Civil, $1^{\mathrm{a}}$ ed., Civitas, Madrid, 2005, pp. 352-353.

${ }^{25}$ Apunta Montero Aroca, J., La prueba en el proceso civil, ob. cit., p. 367, que, a efectos de admisibilidad, se ha equiparado el tratamiento de documentos fundamentales y dictámenes a instancia de parte, y «no existe propiamente una decisión judicial sobre la admisión». 
En la práctica forense, los letrados, al efectuar su proposición oral de los medios de prueba en la audiencia previa, solicitan que se den por reproducidos los documentos y dictámenes acompañados con los escritos de alegaciones. Aun así, el mero olvido de solicitar en la fase de audiencia previa que se tenga por reproducidos los documentos y dictámenes acompañados con los escritos de alegaciones no determina su inadmisión, por resultar una consecuencia procesal desproporcionada, sino que más bien se trata de una irregularidad procesal susceptible de subsanación con un simple recordatorio por parte del juez o incluso estimando que con la aportación inicial se produjo una proposición tácita de los documentos y dictámenes a instancia de parte ${ }^{26}$.

Se ha planteado si puede inadmitirse un documento fundamental aportado con la demanda o un dictamen a instancia de parte. La impugnación del juicio de admisión de los documentos depende, fundamentalmente, del momento de su acceso al proceso (criterio de la temporalidad), que ha permitido a MuÑoz SABATÉ distinguir entre: 1) documentos acompañados, que son los aportados junto con los escritos de alegaciones para dar soporte a las alegaciones que se vierten en los mismos; 2) documentos aportados, que son los presentados aisladamente del cuerpo de alegaciones y comprensivos de: a) los documentos llamados complementarios; b) los documentos cuyo interés o relevancia se puso de manifiesto a consecuencia de las alegaciones del demandado al contestar la demanda (art. 265.3 LEC); c) los documentos que se pueden aportar en un momento no inicial del proceso (art. 270 LEC); d) los documentos que se pueden aportar como diligencia final en sustitución de otros actos de prueba fallidos (art. 435.2 LEC); e) los documentos que se pueden presentar excepcionalmente frente a la regla de la preclusión definitiva (art. 271 LEC); y 3 ) documentos requeridos, que son aquellos que se solicitan o requieren a las otras partes o a un tercero para que proceda a su debida exhibición en el proceso (art. 328, 329 y 333 LEC) $)^{27}$.

Los documentos acompañados -en la terminología de MuÑoz SABATÉson los fundamentales. Al igual que los dictámenes a instancia de parte están

26 La Sentencia de la Audiencia Provincial de Las Palmas, secc. $5^{\mathrm{a}}$, de 16 de noviembre de 2004, FJ $4^{\circ}$ (JUR 2005/25872) razona: «...el mero hecho de que la letrada actora olvidara solicitar que se tuvieran por reproducidos [los documentos], jamás puede comportar una consecuencia tan grave como la pretendida de contrario, donde un simple formalismo procesal o, en este caso, su incumplimiento u omisión, es decir, la no alegación por el letrado de una concreta locución en el acto del juicio: «se tengan por reproducidos los documentos acompañados a la demanda», pudiera tener mayor valor que el propio cumplimiento material de la norma que ahora considera, lo que, en suma, llevaría a una vulneración de su derecho a la tutela judicial efectiva, del que, como garante del mismo, se constituye juez, por mandato constitucional, en su principal protector».

${ }^{27}$ Muñoz Sabaté, L., Fundamentos de prueba judicial L.E.C. 1/2000, Bosch, Barcelona, 2001, pp. 295-304. 
sujetos a la carga de la aportación inicial (art. 265.1.4 LEC), debiéndose aportar junto con la demanda y la contestación a la demanda, bajo sanción de preclusión (art. 269 LEC). La admisión a trámite de la demanda (o, en su caso de la contestación a la demanda) comporta la incorporación de los documentos, y aun cuando técnicamente cabe un recurso de reposición contra la incorporación de un documento aportado con demanda (o, en su caso, de la contestación a la demanda), ello es harto improbable, porque técnicamente la admisión tiene lugar en la audiencia previa (art. 429.2 LEC).

Los documentos fundamentales constituyen el sustento probatorio de las afirmaciones que se vierten en los escritos de alegaciones y, por ende, acceden al proceso con anterioridad a la fijación de los hechos controvertidos (art. 428.1 LEC) y del momento de proposición de los medios de prueba (art. 429.1 LEC), no resultando exigible que la parte, demandante o demandada, realice un examen inicial sobre el carácter esencial de los documentos que se propone incorporar con su demanda o contestación, aun cuando es conveniente que aporte todo lo que sea susceptible de ser aportado en ese momento. En realidad, y como destaca Ramos MéNDEZ, los documentos aportados con los escritos de alegaciones no aparecen condicionados a un juicio de pertinencia previa, a diferencia del resto de las pruebas, lo cual permite incorporar documentos inútiles que posiblemente en un momento posterior no hubiera superado el juicio formal de pertinencia ${ }^{28}$.

El dictamen a instancia de parte se incorpora al proceso con el auto de admisión de la demanda (o, en su caso, el de contestación a la demanda), del mismo modo como acontece con los documentos fundamentales, aun cuando técnicamente la admisión - al igual que los restantes medios de prueba- tiene lugar en la audiencia previa (art. 429.2 LEC). Ahora bien, puede inadmitirse un dictamen a instancia de parte en la medida en que no verse sobre aspectos técnicos, contenga conclusiones jurídicas o verse sobre hechos tan simples que no precisen de conocimientos técnicos o prácticos ${ }^{29}$.

También se ha postulado la devolución del dictamen pericial al aportante por motivos formales, tales como la falta de idoneidad técnica o científica

${ }^{28}$ Ramos Méndez, F., Enjuiciamiento Civil, t. I, Atelier, Barcelona, 2008, pp. 751752, quien, además, afirma «todavía no he visto pedir que se retiren del pleito los documentos aportados con la demanda o con la contestación».

29 Serra Domínguez, M., «La prueba pericial», en Instituciones del nuevo Proceso Civil, Dijusa, Barcelona, 2000, p. 293, afirma que para la admisibilidad de la prueba pericial «bastará simplemente con que los extremos del dictamen pericial tengan carácter técnico, estén relacionados con los hechos del proceso, y no hayan sido admitidos por las partes». La doctrina está divida en favor y en contra de un juicio de pertinencia y utilidad sobre los dictámenes a instancia de parte, pudiéndose ver una posición favorable en Flores Prada, I., La prueba pericial de parte en el proceso civil, Tirant lo Blanch, Valencia, 2005, pp. 275-277 y una posición contraria en Illescas Rus, A. V., La prueba pericial en la Ley 1/2000, de Enjuiciamiento Civil, Aranzadi, Cizur Menor, 2002, p. 245. 
del perito, la falta de juramento o promesa del art. 335.2 LEC, o la omisión de los soportes a que alude el art. 336.2 $\mathrm{LEC}^{30}$, aun cuando probablemente el primer supuesto no afecta tanto a la admisibilidad cuanto a la valoración del dictamen y los otros dos supuestos constituyen exigencias legales subsanables.

\subsection{La limitación del número de testigos.}

El art. 363 LEC, erróneamente rubricado «limitación del número de testigos», cuando en realidad debiera ser «dispensa de la declaración del testigo admitido», dispone que «las partes podrán proponer cuantos testigos estimen por conveniente, pero los gastos que excedan de tres por cada hecho discutido serán en todo caso de cuenta de la parte que los haya presentado».

Dicha norma no constriñe a tres el número de testigos a proponer, sino que efectúa una imputación en los gastos, de manera que la declaración de más de tres testigos por cada hecho discutido deberá ser abonada por la parte proponente. No se restringe el número de testigos a proponer, sino que recoge una norma distributiva del pago de los gastos que deriven de su práctica, estableciendo que respecto de unos mismos hechos discutidos, el coste del cuarto y sucesivos testigos corresponde a la parte proponente ${ }^{31}$, en todo caso y con independencia de que haya o no condena en $\operatorname{costas}^{32}$, y todo ello movido por el afán de potenciar la celeridad del proceso y evitar una sobreabundancia innecesaria de testigos ${ }^{33}$.

Es difícil sostener la constitucionalidad de una norma limitadora del interrogatorio de testigos en función del número de testigos propuestos ${ }^{34}$. Siguiendo a PICó i JUNOY podemos razonar: En primer lugar, porque el interrogatorio de testigos, al igual que los restantes medios de prueba, está sujeto a idénticos parámetros de pertinencia, utilidad o legalidad (art. 283 LEC). En segundo lugar, porque en el momento de efectuar el juicio sobre la admisión de los testigos propuestos todavía se desconoce el alcance de la declaración de tales testigos, por lo que el juez difícilmente podrá motivar o razonar el rechazo in limine de tales testigos. En tercer lugar, porque a pesar de que el juez esté convencido de un hecho, la declaración de nuevos testigos puede aportarle datos que le haga recapacitar sobre el convencimiento provisional adquirido. $\mathrm{Y}$ en cuarto lugar, porque una vez recaído el juicio de pertinencia

${ }^{30}$ Muñoz Sabaté, L., Fundamentos de prueba judicial L.E.C. 1/2000, ob. cit., p. 340.

31 Puede verse la Sentencia del Tribunal Superior de Justicia de Galicia, de 27 de junio de 2003, FJ $2^{\circ}$ (EDJ 2003/114542) en la que el juez da opción a la parte proponente del interrogatorio de testigos para que seleccionara de entre los 25 propuestos a cinco de ellos.

32 Rodriguez Tirado, A. M., «El interrogatorio de testigos», ob. cit., p. 398.

33 Chozas Alonso, J. M., El interrogatorio de testigos en los procesos civil y penal. Su práctica ante los tribunales, La Ley, Madrid, 2010, p. 176.

${ }^{34}$ Asencio Mellado, J. M., «El proceso civil práctico», ob. cit., p. 803. 
y utilidad del interrogatorio de testigos, y admitidos los tetigos, no puede volverse a plantear dicho juicio, salvo que la parte proponente desistiere del testigo (art. 288 LEC) y, aun en este supuesto, con las limitaciones derivadas del principio de adquisición procesal ${ }^{35}$.

Desde un punto de vista de praxis forense, y para evitar el uso indebido de la normativa del art. 363 LEC, limitando anticipadamente la proposición de testigos, merece recogerse la sugerencia de MuÑoz SABATÉ, en el sentido que en caso de gran número de testigos con una patente diversidad de themas probandi pueda el tribunal dirigirse previamente a la parte para que indique si las preguntas que se van a dirigir a los testigos serán todas las mismas o serán diferentes, distinguiendo en éste último caso a quienes depondrán sobre una misma cuestión ${ }^{36}$.

No se indica en el art. 363 LEC si la dispensa de declaración de los testigos admitidos se refiere a los tres de una misma parte proponente. Se plantea por tanto la custión de si la aplicación del art. 363 LEC se refiere a tres testigos de cada misma parte o al conjunto de los testigos que declaran. Se ha defendido, con razón, que, para evitar una infracción del principio de igualdad y al derecho de utilización de los medios de prueba, la referencia a los tres testigos debe aplicarse al conjunto de los tres testigos propuestos por una misma parte ${ }^{37}$. A efectos prácticos, y cuando todos los testigos admitidos hayan de declarar sobre unos mismos hechos controvertidos, entiendo que la limitación del art. 363 LEC podría incluso operar habiendo escuchado el juez ya la declaración de dos testigos por cada una de las partes, siendo oportuno, en todo caso, consignar en el acta las circunstancias concurrentes (STSJ Galicia, 15 octubre $2004^{38}$ ).

De operarse la limitación del número de testigos, y dispensarse la declaración de un testigo y admitido, una vez citado y comparecido a la sede del juzgado, el testigo tendrá derecho a reclamar la indemnización que pueda corresponderle por los gastos y perjuicios que su comparecencia les haya

35 Picó i Junoy, J., «Interrogatorio de testigos y admisión. ¿Pueden las partes proponer cuantos testigos estimen por conveniente o existe alguna limitación (art. 363 LEC)?», en La audiencia previa, Boch, Barcelona, 2010, pp. 405-407.

36 Muñoz Sabaté, L., Fundamentos de prueba judicial civil L.E.C., ob. cit., p. 360.

37 Queral Carbonell, A., «Dispensa de la declaración del testigo admitido», en El interroatorio de testigos, Bosch, Barcelona, 2008, p. 304.

${ }^{38}$ Sentencia del Tribunal Superior de Justicia de Galicia, secc. $1^{\text {a }}$, de 15 de octubre de 2004, FJ $2^{\circ}$ (EDJ 2004/267996): «El motivo por el que se denuncia la infracción del art. 460.2 no puede prosperar puesto que, como ya señaló la Audiencia Provincial al rechazar el recibimiento a prueba, la posibilidad de practicarla en segunda instancia se configura en nuestro ordenamiento como excepcional y no existe infracción procesal alguna por el hecho de que el Juez de Primera Instancia hubiese procedido conforme le autoriza el artículo 363 LEC, limitando el número de testigos y consignando tal circunstancia en el acta, considerándose ilustrado con el testimonio de tres de ellos»». 
ocasionado, aun cuando la literalidad del art. 375 LEC [ «los testigos que declaren...»] pudiera inducir a pensar que es presupuesto de la indemnización el hecho efectivo de la declaración, puesto que el objeto de la indemnización no es la declaración en sí misma, sino los gastos (transporte, horas de trabajo, etc.) derivados del desplazamiento a la sede judicial, sin que pueda ser de peor condición el testigo comparecido y cuya declaración se renuncia por la parte proponente frente al testigo comparecido y que ha declarado ${ }^{39}$.

\section{LA IMPUGNACIÓN DE LA RESOLUCIÓN SOBRE LAADMISIBILIDAD DE LAS PRUEBAS.}

La resolución sobre el juicio de admisión de los medios de prueba es recurrible en reposición. Así se desprende del art. 285.2 LEC, ubicado en el capítulo correspondiente a las disposiciones generales sobre la prueba, que literalmente dispone «contra esta resolución [admisión de cada una de las pruebas que hayan sido propuestas] cabrá un recurso de reposición, que se sustanciará y resolverá en el acto, y si se desestimara, la parte podrá formular protesta al efecto de hacer valer sus derechos en la segunda instancia».

La resolución judicial es recurrible, cuando menos respecto al juicio ordinario. Y tanto respecto a la inadmisión, cuanto respecto a la admisión, novedad ésta última con respecto a la LEC de 1881, que ha merecido un juicio doctrinal favorable y unánime. De este modo se supera cierta orientación jurisprudencial que estimaba que la admisión de prueba nunca podía ocasionar perjuicios. Ejemplo de esta orientación era, entre otras, la STS de 15 de diciembre de 1993, en cuyo fundamento jurídico segundo se razonaba que «así como la denegación de un medio de prueba [...] puede suponer indefensión para la parte que lo propuso [...], en cambio la admisión por el juzgado de un medio de prueba [...] no es concebible que pueda entrañar indefensión alguna, [dado que la parte] siempre dispone de la posibilidad de proponer también todos los medios de prueba que considere procedentes.... ${ }^{40}$.

Frente a la admisión o inadmisión de un medio de prueba se articula un recurso de reposición oral, de interposición, substanciación y resolución en el mismo acto de la audiencia previa. Aun cuando algún autor ha apuntado el carácter extraño de una reposición que se sustancia y se decide de modo oral $^{41}$, y ciertamente la normativa del art. 285 LEC, al consagrar un recurso

${ }^{39}$ Del Valle García, M., «Indemnización del testigo y dispensa de declaración», en El interrogatorio de testigos, Bosch, Barcelona, 2008, pp. 421 y 422.

${ }^{40}$ Sentencia del Tribunal Supremo, Sala $1^{\mathrm{a}}$, de 15 de diciembre de 1993 , FJ $4^{\circ}$ (RJ 1993/9988).

${ }^{41}$ Montero Aroca, J., La prueba en el proceso civil, ob. cit., p.197, razona: «en los actos orales, en los que se dictan resoluciones orales, que se documentan en el acto, no debería caber recurso de reposición, pues éste tiene siempre tramitación escrita (arts. 451 a 454 LEC), sino sólo expresión de protesta. Con todo, el artículo 285.2 regula una extraña reposición que se sustancia y decide de modo oral. Se trata que el legislador no 
de reposición ad hoc frente a la admisión o inadmisión de los medios de prueba, constituye una norma especial frente al recurso de reposición general, de tramitación y resolución escrita (art. 451 y ss. LEC), no debemos olvidar que tanto la proposición cuanto la resolución de los medios de prueba tiene lugar en un acto presidido por la oralidad, como es la audiencia previa, y que es intención del legislador que todo cuanto pueda resolverse en este momento no se difiera ni aplace para un momento posterior.

En materia de juicio verbal existe una previsión específica, conforme a la cual "contra las resoluciones del tribunal sobre inadmisión de pruebas o sobre admisión de las que se denunciaran como obtenidas con violación de derechos fundamentales, las partes podrán formular protesta a efecto de hacer valer sus derechos en la segunda instancia" (art. 446 LEC).

La contradicción entre el artículo 285 LEC (que regula un recurso de reposición oral en sede de disposiciones generales sobre la prueba) y el artículo 446 LEC (que regula la protesta, limitada a la inadmisión de los medios de prueba o la admisión de los admitidos con violación de derechos fundamentales en sede del juicio verbal) debe resolver a favor de la admisión de un recurso de reposición también en el juicio verbal. Y no solamente por una interpretación sistemática de la LEC, sino también por resultar lo más ajustado al derecho a la tutela judicial efectiva (art. 24.2 CE) en su vertiente del derecho a los recursos, sin que tal solución pueda entenderse que distorsione la estructura sencilla y rápida del juicio verbal. La opción contraria, de admitir el recurso de reposición en el juicio ordinario y solamente la protesta en el verbal, crea una injustificable distinción entre ambos tipos de juicios en un extremo relevante, la facultad de las partes de oponerse a la decisión judicial sobre la admisión o inadmisión de los medios de prueba, que forma parte del derecho a la tutela judicial efectiva, en su vertiente del acceso a los recursos ${ }^{42}$. Tampoco faltan posiciones más matizadas que admiten tanto la formulación de protesta como la de reposición previa, considerándose que, a efectos prácticos la reposición viene a equivaler a una mera protesta, en la que el juez resolverá de modo oral, normalmente reiterando su resolución ${ }^{43}$.

\section{LA FACULTAD JUDICIAL DE INTEGRACIÓN PROBATORIA (ART. 429.1, II Y III LEC).}

Un examen sobre la normativa del art. 429.1, II y III LEC exige referirse a su denominación -facultad judicial de integración probatoria-, su funda-

ha entendido lo que es propiamente un acto oral».

${ }^{42}$ En este sentido Díaz Fuentes, A., La prueba en la nueva Ley de Enjuiciamiento Civil. $2^{\text {a }}$ ed., Bosch, Barcelona, 2004, p. 70; FAchal Noguer, N., «La disconformidad con la resolución sobre admisión o inadmisión de los medios de prueba», en Aspectos prácticos de la prueba civil, Bosch, Barcelona, 2006, pp. 190-195.

${ }^{43}$ Bonet Navarro, J., La prueba en el proceso civil. Cuestiones fundamentales, Dijusa, Barcelona, 2009, p. 173. 
mento, su contenido -facultad de indicación y facultad de sugerencia-, sus presupuestos y límites, y la actuaciones de las partes y del tribunal, de lo que ya nos hemos ocupado extensamente en otro lugar ${ }^{44}$.

A nuestro entender la normativa del art. 429.1, II y III LEC comporta una facultad judicial de integración probatoria, como han recogido ya algunas resoluciones de la jurisprudencia menor (SAP Baleares, de 3 de mayo de 2005. marzo de $2008^{47}$ ), cuyo fundamento obedece a una compensación en tramitación parlamentaria, por la pérdida de poder del juez, a raíz de la supresión de las diligencias para mejor proveer. Confiere al juez la facultad de indicar la insuficiencia de las pruebas propuestas y el hecho o hechos afectados por la eventual insuficiencia, así como proponer las pruebas para paliarla, suscitándose la controvertida cuestión de si el juez puede sugerir una prueba (ej. documentos fundamentales o dictámenes) cuyo estadio procesal ya ha precluido ${ }^{48}$.

Tres son los presupuestos de la normativa del art. 429.1, II y III LEC. En primer lugar, la existencia de hechos controvertidos, porque en su defecto no se abre el período probatorio. En segundo lugar, la previa proposición por las partes, puesto que el juez al amparo de la tantas veces citada normativa no puede suplir la inactividad de las partes ni la subsanación de prueba no propuestas o propuestas inadecuadamente por no sujetarse a las previsiones de la LEC. Y en tercer lugar, la existencia de un juicio eventual de insuficiencia

44 Abel Lluch, X., Iniciativa probatoria de oficio en el proceso civil, Bosch, Barcelona, 2005, pp. 111-182, y más recientemente, Derecho Probatorio, Bosch, Barcelona, 2012, pp. 149-166.

45 Sentencia de la Audiencia Provincial de Baleares, secc. $3^{\text {a }}$, de 3 de mayo de 2005, FJ $2^{\circ}$ (JUR 2005/119239): «...En definitiva, la nueva norma introduce un mecanismo para facilitar la convicción judicial sobre los hechos controvertidos mediante la facultad de integración probatoria, pero no impone al juez un deber de controlar la suficiencia probatoria en la inicial fase de la audiencia previa y con la posibilidad que sea un juez distinto el que dicte sentencia, ni existe una garantía absoluta que, aun con indicación de insuficiencia probatoria, las nuevas pruebas acrediten los hechos controvertidos, todo ello sin olvidar que la normativa de la carga de la prueba del artículo 217 de la LEC, que opera al tiempo de dictar sentencia, no se halla supeditada al uso de la facultad del artículo 429». (La cursiva es nuestra)

46 Sentencia de la Audiencia Provincial de Madrid, secc. 14 ${ }^{\text {a }}$, de 27 de octubre de 2005, FJ $2^{\circ}$ (AC 2005/2138).

${ }^{47}$ Sentencia de la Audiencia Provincial de Málaga, secc. $5^{\text {a }}$, de 3 de marzo de 2008, FJ $3^{\circ}$ (AC 2008/1260).

48 Puede verse la posición contraria de Pico i Junoy, J., en La audiencia previa, Bosch, Barcelona, 2010, pp. 383-392 y la más matizada de CHICo Fernández, T., «La carga de la prueba y la iniciativa probatoria de oficio», en Objeto y carga de la prueba civil, Bosch, Barcelona, 2007, pp.148-151. 
probatoria que se trata de «una apreciación subjetiva que difícilmente podrá ser objeto de un control externo y a posteriori por otro órgano judicial para imponerle su propio criterio» (SAP Navarra, de 16 de abril de $2002^{49}$ ).

Los límites de dicha facultad, siguiendo a PICÓ i JUNOY, son dos. Primero, el juez no podrá introducir hechos distintos de los alegados por las partes, respetándose así el principio dispositivo. Y segundo, el juez no podrá utilizar fuentes probatorias distintas de las existentes en las actuaciones, protegiéndose así la debida imparcialidad judicial ${ }^{50}$. Y junto a estos límites, la iniciativa probatoria de oficio contenida en el art. 429.1, II y III LEC reclama una garantía, común a la práctica de toda prueba, sea instancia de parte o de oficio, como es la práctica contradictoria de las pruebas.

La indicación de insuficiencia probatoria no vincula a las partes quienes podrán, o no, completar o modificar sus proposiciones iniciales de prueba (art. 429.1, III LEC). Dicha indicación puede tener un «efecto de advertencia» sobre la insuficiencia de prueba, bien un «efecto de sugerencia» sobre la concreta prueba para paliar tal insuficiencia, o bien un «efecto recordatorio» cuando existió un mero olvido en la proposición de prueba. Tras la indicación las partes podrán efectuar alegaciones, e incluso solicitar una interrupción, aun cuando tal trámite no esté legalmente previsto, en aras a salvaguardar el derecho de defensa. Pero no podrán reclamar que el juez sugiera qué prueba estima conveniente, ni completar su prueba sobre hechos distintos de los sugeridos por el juez. Las partes podrán recurrir en reposición la resolución que admite o deniega las pruebas, a raíz de la indicación de insuficiencia probatoria, pero no la «indicación» de insuficiencia probatoria, dado que técnicamente no es una resolución.

El juez no podrá acordar la prueba de oficio, si las partes desatienden la indicación de insuficiencia probatoria, pues con ello quebraría el principio de aportación de parte. La práctica de la prueba de oficio no encaja con la redacción del art. 429.1, II y III LEC que, tras la indicación de insuficiencia probatoria (párrafo segundo), reserva a las partes la posibilidad de «modificar o completar» sus proposiciones iniciales (párrafo tercero) y utiliza unos términos indicativos («señalar») cuando hubiera podido utilizar unos más imperativos (acordará, decretará, ordenará) ${ }^{51}$.

49 Sentencia de la Audiencia Provincial de Navarra, secc. $2^{\mathrm{a}}$, de 16 de abril de 2002, FJ $5^{\circ}$ (JUR 2002/142806).

${ }^{50}$ Picó i Junoy, J., Los principios del proceso civil, ob. cit., pp. 38 y ss., y también El juez y la prueba. Estudio de la errónea recepción del brocardo iudex iudicare debet secundum allegata et probata, no secundum conscientiam y su repercusión actual, Bosch, Barcelona, 2007, pp.117-118.

51 Entre otras muchas puede verse Sentencia de la Audiencia Provincial de Baleares, secc. $4^{\mathrm{a}}$, de 29 de marzo de 2004, FJ $2^{\circ}$ (EDJ 2004/45861): «La facultad concedida por el precepto trascrito no habilita para acordar la práctica de un medio probatorio concreto ni legitima, por tanto, su práctica de oficio, sino que, por el contrario, exclusivamente au- 
La crítica más incisiva frente a la normativa del art. 429.1, II y III LEC es la relativa a la pérdida de la imparcialidad judicial ${ }^{52}$. No pueden ignorarse los riesgos de un uso imprudente de la tal facultad, pero su uso moderado, respetuoso con los presupuestos, límites y garantías descritos no merma la imparcialidad judicial desde el momento que la indicación de insuficiencia probatoria no se dirige a una de las partes, sino a ambas. Además, en el momento de efectuar la indicación de insuficiencia probatoria el juez desconoce el resultado de la prueba a practicar y cuál de las partes beneficiará. Tampoco podemos olvidar que los artículos que reconocen la iniciativa probatoria de oficio no han sido declarados inconstitucionales ni en los procesos civiles no dispositivos, ni tampoco en el proceso administrativo, ni en el laboral ni siquiera en el penal.

No puede exigirse responsabilidad al Letrado que decide no «completar o modificar» (art. 429.1, III LEC) su proposición inicial de prueba, a la vista de la «sugerencia» del juez, si posteriormente se desestima la demanda por falta de prueba de los hechos indicados por el juez. La indicación judicial de insuficiencia probatoria, no obstante el «efecto psicológico» que ejerce sobre el letrado, no es vinculante, y el letrado puede o no atender la indicación de insuficiencia probatoria.

Por otra parte, algún autor ha propuesto que la desatención por un litigante a una manifestación de insuficiencia probatoria efectuada por el tribunal pueda utilizarse como indicio endoprocesal contrario a la parte que no ha querido proponer o aportar prueba al proceso ${ }^{53}$. Se trata de una conclusión muy discutible, porque amén de presuponer que la indicación judicial era correcta y acertada para resolver la controversia, no resulta respetuosa con el

toriza al Tribunal como una consecuencia directa de la previsión contenida en el artículo 428.1 LEC (fijación de hechos controvertidos y de la proposición de pruebas por las partes, art. $429-1^{\circ}$ LEC ) limitándose la facultad a poner de manifiesto a las partes, con fundamento en la proposición de prueba ya realizada, aquellos hechos controvertidos que, a juicio del Tribunal podrían quedar insuficientemente probados con la prueba propuesta por las partes, por lo que la citada facultad se configura como un juicio de valor del Tribunal en relación con los hechos controvertidos y la prueba propuesta que pone de manifiesto a las partes sin vinculación alguna de éstas». En sentido similar Sentencia de la Audiencia Provincial de Santa Cruz Tenerife, secc.1 ${ }^{a}$, de 19 de mayo de 2003, FJ $4^{\circ}$ (EDJ 2003/124782).

52 Tampoco faltan otras críticas basadas en una concepción autoritaria del proceso, como la de Montero Aroca, J., La prueba en el proceso civil, ob. cit., pp. 517-533. Con carácter más general pueden verse las posiciones contrapuestas de PICÓ i JunOY, J., «El derecho procesal entre el garantismo y la eficacia: Un debate mal planteado», pp.110-127, y Montero ArocA, J., «El proceso civil llamado "social” como instrumento de "justicia" autoritaria», pp.129-165, en Proceso Civil e ideología, obra coordinada por éste último autor, ed. Tirant lo Blanch, Valencia, 2006.

53 Seone Spielgeberg, J. L., La prueba en la Ley de Enjuiciamiento Civil 1/2000. Disposiciones Generales y Presunciones, 2a ed., Aranzadi, Cizur Menor, 2007, p. 124. 
principio de aportación de parte. Corresponde a las partes la proposición de la prueba, y los efectos de la falta de probanza deben ser valorados conforme a las reglas de la carga de la prueba (art. 217 LEC).

Desde el derecho positivo, la única consecuencia prevista es que la parte que desatiende la indicación judicial no puede proponer, como diligencia final, las pruebas que hubiera podido proponer tras la manifestación del art. 429.1, II LEC (art. 435.1.1 in fine LEC).

\section{EL SEÑALAMIENTO DEL JUICIO.}

Una vez admitidos los medios de prueba deberá procederse, en la misma audiencia previa, al señalamiento del acto del juicio, que deberá tener lugar en el plazo de un mes desde la conclusión de la audiencia previa o, a solicitud de la parte, en el plazo de dos meses cuando toda o parte de la prueba tenga que practicarse fuera del lugar de la sede del Juzgado (art. 429. 2 y 3 LEC), resultando práctico advertir a las partes que comparezcan a las audiencias previas con sus agendas de señalamiento para evitar las solicitudes de nuevos señalamientos por coincidencia de juicios no detectadas ${ }^{54}$.

También en la misma audiencia previa se procederá a la citación de la partes. Los testigos y los peritos podrán ser presentados por las propias partes, en cuyo caso no serán citados. Las partes podrán pedir la citación de testigos o peritos por la vía ordinaria y, en su caso, por medio de auxilio judicial. En este último supuesto, deberán presentar una lista de preguntas dentro de los tres días siguientes a la admisión del interrogatorio de testigos (art. 429.5 LEC).

Existe un supuesto en el que el tribunal puede dictar sentencia, dentro de los veinte días siguientes a la celebración de la audiencia previa y sin apertura del periodo probatorio: cuando las únicas pruebas propuestas sean documentos y éstos no se hubieren aportado, o cuando se hayan propuesto dictámenes periciales y ni las partes ni el tribunal solicitaren la presencia de los peritos para ratificación de su informe (art. 429.8 LEC).

Se ha planteado si cabe atender la petición de las partes de formular conclusiones en aquellos supuestos en que no hay acto del juicio (art. 429.8 LEC) y se procede, una vez finalizada la audiencia previa, a declarar los autos conclusos para sentencia. El art. 429.8 LEC prevé la posibilidad que terminada la audiencia previa, y sin acordar señalamiento del acto del juicio, se dicte sentencia dentro de los veinte días siguientes a aquel en que termine la audiencia previa, en aquellos supuestos en que las únicas pruebas propuestas fueran unos documentos, y éstos ya se hubieran aportado al proceso

${ }^{54}$ Diego, M., «Juicio ordinario. Audiencia previa. Proposición y admisión de la prueba. Señalamiento del juicio. Art. 429 Ley de Enjuiciamiento Civil», en Cuestiones prácticas de la audiencia previa en el juicio ordinario, Cuadernos de Derecho Judicial núm. II/2008, CGPJ, Madrid, 2009, p. 316; RodríGUEz ACHÚTEGUI, E., «Comentario al art. 429 LEC», en Enjuiciamiento Civil, t.II, Sepin, Madrid, 2008, p. 2652. 
sin resultar impugnados, o unos dictámenes periciales, y ni las partes ni el tribunal solicitara la presencia de los peritos en el juicio para la ratificación de su informe, dado que en tales supuestos carece de razón de ser la práctica de la prueba, por haber ya quedado perfilada en la audiencia previa ${ }^{55}$. Por su parte, el art. 433.2 LEC prevé que, una vez finalizado el acto del juicio y practicadas las pruebas, las partes formulen oralmente sus conclusiones sobre los hechos controvertidos ${ }^{56}$.

Como regla general, y es habitual, las conclusiones tienen lugar en el acto del juicio y tras la práctica de la prueba, pues versan sobre las pruebas que se han practicado en dicho acto (interrogatorio de las partes, interrogatorio de testigos, ratificación de peritos, fundamentalmente), amén de las que se hayan acompañado con los escritos de alegaciones iniciales (documentos, dictámenes a instancia de parte, informes de detectives).

Si el tribunal, una vez terminada la audiencia previa, decide no acordar el señalamiento del acto del juicio, por concurrir los supuestos del art. 429.8 LEC, se guarda silencio sobre la posibilidad de unas conclusiones. No veo inconveniente para que se acuerde un breve trámite de conclusiones, mayormente cuando las partes lo interesen ${ }^{57}$, que, por definición, deberá circunscribirse a la valoración de las pruebas (documentos, dictámenes a instancia de parte, informe de detectives) que ya figuren en las actuaciones, pudiendo incluso resultar más práctico que en vez de un informe de conclusiones que el tribunal pueda requerir de cada una de las partes que le ilustre sobre un punto o puntos controvertidos en particular ${ }^{58}$.

Con respecto a la práctica de la prueba se ha planteado si en los supuestos de interrogatorio de la parte domiciliario (art. 311 LEC), a través de auxilio judicial (art. 313 LEC), o de entidades públicas (art. 315 LEC) deben presentarse las preguntas en el momento de la proposición de prueba en la audiencia previa.

55 Tapia Ferández, I, «Comentario al art. 430 LEC, en Comentarios a la nueva Ley de Enjuiciamiento Civil, vol. I, Aranzadi, Cizur Menor, 2001, p. 1465.

56 Sobre los requisitos de forma y de contenido de las conclusiones puede verse SoLano Martín, M., «Incidencia de la oralidad en la formulación de las conclusiones: de la instructa a las conclusiones orales», en Aspectos prácticos de la prueba civil, Bosch, Barcelona, 2006, pp. 560-564.

57 Rodrigúez Achútegui, E., «Comentario al art. 429 LEC», en Enjuiciamiento Civil, t. II, Sepin, 2008, p. 2651 afirma «...no hay conclusiones como en el caso del art. 433.2 LEC, porque no hay juicio (Sentencia de la Audiencia Provincial de Madrid de 18 de enero de 2005). Sin embargo, es indudable que no se causa indefensión por permitir a las partes, si éstas lo solicitan, que se evacuen brevemente».

58 En sentido distinto Banacloche Palao, J., «Comentario al art. 429 LEC», en AAVV Comentarios a la Ley de Enjuiciamiento Civil, Civitas, Madrid, 2001, p. 727, para quien «al no haber prueba practicada, tampoco hay conclusiones, que tienen como finalidad valorar los resultados de aquélla». 
El interrogatorio de las partes, como regla general, deberá practicarse en el acto del juicio, debiéndose formular las preguntas oralmente (art. 302 LEC), con lo que se da cumplimiento al mandato constitucional de primer la oralidad en las actuaciones procesales (art. 120.2 CE) y no se exige a las partes que aporten un listado de preguntas, a diferencia de la derogada LEC, que reclamaba un pliego de posiciones por escrito (art. 582 LEC 1881).

La regla general de la oralidad en la formulación de las preguntas del interrogatorio de las partes, quiebra en los supuestos del interrogatorio de la parte domiciliario (art. 311 LEC), a través de auxilio judicial (art. 313 LEC) o de entidades públicas (art. 315 LEC), en los que deberá presentarse un listado de preguntas, a responder por la parte interrogada, suscitándose la duda del momento procesal en que deben aportarse las preguntas y si dicho momento procesal es la audiencia previa u otro posterior. Para resolver adecuadamente la cuestión planteada debemos analizar separadamente cada uno de los supuestos planteados:

1) El interrogatorio de las entidades públicas. El art. 315.1 LEC dispone que «Cuando sea parte en un proceso el Estado, una Comunidad Autónoma, una Entidad local y otro organismo público, y el tribunal admita su declaración, se les remitirá, sin esperar al juicio o a la vista, un lista con las preguntas que, presentadas por la parte proponente en el momento en que se admita la prueba, el tribunal declare pertinentes,...». De la literalidad legal se desprende que la lista de preguntas debe aportarse en la audiencia previa del juicio ordinario o en la vista del juicio verbal ${ }^{59}$, pues la posibilidad que se aporte el interrogatorio de preguntas con la demanda, tiene el inconveniente que aun no se han fijado los hechos controvertidos y no existen datos para valorar la pertinencia ${ }^{60}$.

2) El interrogatorio domiciliario. El art. 311 LEC dispone que: «1. En el caso que por enfermedad que lo impida o por otras circunstancias especiales de la persona que haya de contestar a las preguntas no pudiera ésta comparecer en la sede del tribunal, a instancia de parte o de oficio, la declaración se podrá prestar en el domicilio o residencia del declarante ante el juez o el miembro del tribunal que corresponda, en presencia del Secretario Judicial. 2. Si las circunstancias no lo hicieran imposible o sumamente inconveniente, al interrogatorio domiciliario podrán concurrir las demás partes y sus abogados. Pero, si a juicio del tribunal, la concurrencia de éstos y aquéllas no resultare procedente teniendo en cuenta las circunstancias de la persona y del lugar, se celebrará el interrogatorio a presencia del tribunal y del Secretario Judicial,

59 Asencio Mellado, J. M., «El proceso civil práctico», ob. cit., p. 404; FernándeZ Urzainqui, F. J., «Comentario al art. 315 LEC», en Comentarios a la nueva Ley de Enjuiciamiento Civil, t. II, ob. cit., p. 1497.

${ }^{60}$ Cremades Morant, J. B., «Comentario al art. 315 LEC», en Enjuiciamiento Civil, vol. II, Sepin, 2008, p. 2042. 
pudiendo presentar la parte proponente un pliego de preguntas para que, de ser consideradas pertinentes, sean formuladas por el tribunal».

De ahí que quepa distinguir un doble modalidad de interrogatorio domiciliario: a) con presencia de las partes y de sus abogados, en cuyo caso las preguntas de formularán oralmente y en el acto; b) sin presencia de las partes y de sus abogados, en cuyo caso la parte proponente debe presentar un pliego de preguntas, que deberá aportarse en el momento en que el juez acuerde que no concurrirán las partes y los abogados, y puede ser en la propia audiencia previa o en un momento posterior, siendo conveniente que la no asistencia de partes y letrados se acuerde con anterioridad al día señalado para la práctica de la prueba para permitir a la parte proponente redactar su listado de preguntas.

3) El interrogatorio por vía de auxilio judicial. El art. 313 LEC establece que «Cuando la parte que hubiese de responder al interrogatorio resida fuera de la demarcación judicial del tribunal, y exista alguna de las circunstancias a que se refiere el párrafo segundo del apartado cuarto del artículo 169, aquélla podrá ser examinada por vía de auxilio judicial. En tales casos, se acompañará al despacho una relación de preguntas formuladas por la parte proponente del interrogatorio, si ésta así lo hubiera solicitado por no poder concurrir al acto del interrogatorio. Las preguntas deberán ser declaradas pertinentes por el tribunal que conozca del asunto»».

Nuevamente cabe distinguir una doble modalidad de interrogatorio por auxilio: a) con concurrencia de las partes al acto del interrogatorio, en cuyo caso, y a pesar del silencio legal, entiendo que las preguntas se podrán formular oralmente, por ser la regla general, no obstante la previsión que tengan que ser declaradas pertinentes por el tribunal que conozca del asunto ${ }^{61}$, habiéndose propuesto en tales supuestos el uso de la video conferencia ${ }^{62}$; b) sin concurrencia de las partes al acto del interrogatorio, en cuyo caso y de conformidad con el art. 429.5 LEC, las partes deben presentar su listado de preguntas dentro de los tres días siguientes a que el tribunal acuerde el interrogatorio por vía de auxilio judicial.

\section{CONCLUSIONES.}

Tras analizar diversos aspectos relativos a la función de proposición y admisión de los medios de prueba en la audiencia previa, nos interesa destacar los siguientes aspectos.

${ }^{61}$ En sentido distinto Asencio Mellado, J. M., «El proceso civil práctico», ob. cit., p. 393, para quien el control de las preguntas tanto en los supuestos de concurrencia como en los de no concurrencia de las partes corresponde siempre al tribunal que conozca del asunto, no al exhortado.

62 JimÉnez Conde, F., El interrogatorio de las partes en el proceso civil, Civitas, Madrid, 2007, p. 150. En sentido similar, también Fons RodríGuEz, C., «Declaración mediante exhorto y videoconferencia», en El interrogatorio de partes, Bosch, Barcelona, 2007, pp. 207-213. 
Primero: Con la finalidad de evitar «tiempos muertos» la LEC, a diferencia de la derogada LEC 1881, opta por el impulso de oficio en el recibimiento del juicio a prueba y en la proposición de los medios de prueba, que se producirá cuando existan hechos controvertidos, aun sin mediar petición de las partes.

Segundo: La proposición de los medios de prueba se efectúa oralmente en la audiencia previa, existiendo un usus fori consistente en el acompañamiento de una minuta escrita con un listado de los medios propuestos, que facilita el juicio de admisión por el juez y la citación de peritos y testigos. Una vez recaído el juicio de admisión de los medios de prueba, y salvo conformidad de ambas partes, no cabe renunciar a un medio de prueba propuesto.

Tercero: El juicio de admisión de los medios de prueba debe configurarse como un deber judicial, cuyos presupuestos son la proposición de los medios de prueba y la fijación de los hechos controvertidos y sus parámetros la pertinencia, la utilidad y la legalidad. Se traduce en una resolución oral, individualizada, motivada, expresa y recurrible, y en caso de duda es preferible incurrir en un exceso en la admisión que en la inadmisión.

Cuarto: No debe confundirse la legalidad (art. 281.3 LEC), que es un parámetro de admisión de los medios de prueba y que se refiere a la observancia de las garantías de tiempo y forma en la proposición de los medios de prueba, con la ilicitud (art. 287 LEC), que es un incidente contradictorio para la expulsión de la prueba admitida con infracción de los derechos fundamentales.

Quinto: Aun cuando técnicamente la admisión de los documentos fundamentales y los dictámenes en los escritos iniciales se produce en la audiencia previa, y una vez fijados los hechos controvertidos, existe la carga de su aportación inicial con la demanda y la contestación a la demanda, bajo sanción de preclusión.

Sexto: El artículo 363 LEC no contiene una limitación del número de testigos a proponer, sino que efectúa una imputación en los gastos, de manera que la declaración de más de tres testigos por cada hecho discutido deberá ser abonada por la parte proponente. A efectos prácticos, y cuando exista un gran número de testigos propuestos, el tribunal puede dirigirse a la parte proponente para que indique si las preguntas que se van a dirigir a los testigos versarán sobre un mismo objeto o distintos objetos.

Séptimo: El artículo 429.1, II y III LEC contiene una novedosa facultad de integración probatoria, que presupone la existencia de hechos controvertidos, la previa proposición por las partes y la existencia de un eventual juicio de insuficiencia probatoria, sin que, de valerse el juez de tal facultad, pueda introducir hechos distintos de los alegados por las partes, ni utilizar fuentes probatorias distintas de las existentes en las actuaciones.

Octavo: La función probatoria de la audiencia previa termina con el señalamiento del acto del juicio y para acordar su duración, resulta oportuno 
ponderar la complejidad de la cuestión litigiosa y la cantidad de pruebas admitidas en la audiencia previa y su previsible duración.

TITLE: The function of proposition and admission of evidence in the preliminary hearings.

RESUMEN: Una de las novedades de la ley 1/2000, de 7 de enero, de Enjuiciamiento Civil, ha sido la introducción de un trámite oral saneador, después de la fase de alegaciones, en la que el legislador ha concentrado una pluralidad de funciones, desde la función conciliadora a la función de proposición y admisión de prueba, pasando por la función saneadora y la función delimitadora de los términos del debate. En el presente artículo se analiza la función probatoria de la audiencia previa, y cada uno de los aspectos contenidos en los artículos 429 y 430 LEC, desde la forma y modo de proponer los medios de prueba, hasta los caracteres y presupuestos del juicio de admisión de los medios de prueba, pasando por la novedosa facultad de indicación de insuficiencia probatoria, para terminar con los aspectos relativos al señalamiento del juicio.

PALABRAS CLAVE: Ley de Enjuiciamiento civil, audiencia previa, función de proposición y admisión de los medios de prueba.

ABSTRACT: One of the innovations of Civil Procedural Law 1/2000 of January 7th, 2001 is the introduction of a preliminary oral hearing following the parties' initial allegations. In drafting the 2001 law, legislators set several goals for this preliminary oral hearing, ranging from the conciliation of the dispute, the proposition and admission of evidence, to the elimination of procedural obstacles and the identification of the issues under dispute. This article analyses the legislative goal of the proposition and admission of evidence in preliminary hearings, and each provision contained in Articles 429 and 430 of Civil Procedural Law 1/200. This includes how the evidence is proposed to the prerequisites of the admission of evidence, faculty to rule that the evidence is not sufficient, and aspects related to the date of the trial.

KEY WORDS: Civil Procedural Code, preliminary hearing, function of the propositions, admission of evidence.

Recibido: 24.07.2012

Aceptado: 18.10 .2012 